\title{
Psychophysiological mechanisms of mental stress reactions in patients with "hypertension at work" and patients with essential Hypertension: a comparative analysis
}

\author{
Yury P. Zinchenko ${ }^{a}$, Elena I. Pervichko ${ }^{a}$, Olga D. Ostroumova ${ }^{b}$ \\ ${ }^{a}$ Lomonosov Moscow State University, Moscow, Russia \\ ${ }^{b}$ Moscow State Medical Dental University, Treatment Faculty, Moscow, Russia
}

In the study, psychological and physiological features were assessed during an experimentally designed stressful situation in 85 subjects with hypertension (HTN) in the workplace, 85 patients with essential HTN, and 82 healthy individuals.

It was showed, that patients with HTN in the experimental situation were characterized by a complex of physiological and psychological features, which distinguish them from healthy participants. A reliably greater increase In systolic blood pressure (BP) was recorded in these patients in comparison with healthy individuals (on average by 14 and $3 \mathrm{mmHg}$ respectively). The aspiration level (AL) of these patients was characterized by a reliably greater height, inadequacy, and instability; as for nonverbal behavior, it revealed a reliably greater amount of gestures, and frequent changes in voice tone against similar features of healthy individuals.

The group of patients with HTN at work, when compared with essential HTN patients, was characterized by a reliably greater increase of systolic BP (on the average by 16 and $4 \mathrm{mmHg}$ respectively) as a reaction to emotional stress. The systolic BP increase in this group was revealed in combination with an initially reliably lower catecholamines' level (CA), a gradual decrease of CA level in urine, and renin and angiotensin- 1 in blood plasma during the experiment. This combination is an indicator of chronic stress and psychophysiological exhaustion. The patients did not manifest any increase of anxiety during the experiment; they were characterized, however, by a greater frequency of $\mathrm{AL}$ inadequacy and instability. The behavior of patients with HTN at work during the experiment was marked by a limited repertory of poses and gestures, but more vigorous facial expressions, and frequent pitch jumps. Obtained results lead us to confirm that the repression of emotions comes as a significant pathogenetic factor in the genesis of psychosomatic syndrome among patients with HTN at work, as opposed to patients with essential HTN.

Keywords: hypertension at work, essential hypertension, mental stress, state anxiety, psychophysiological mechanisms, aspiration level, emotion regulation, repression of emotions. 


\section{Problem statement and motivation}

Hypertension (HTN) and related complications remain among the main problems in contemporary medicine and clinical psychology. In recent years a stable tendency of cardiologic disease to grow younger has been noted. The tendency is usually related to the penetrating effect of stress on modern society, while most able and vigorous people fall prey to it. Nowadays an increasing number of patients have been identified whose blood pressure (BP) indices at work are higher than during free time. This HTN form was called "HTN at work" (Stork J., et al., 1992). HTN at work today is found to be one of the most frequent forms of stress-induced HTN (Karasek, 1998; Light, 2000).

The vital importance of early detection, treatment and prevention of the stressinduced HTN is believed to be spurring a revival of interest in psychological models of psychosomatic syndrome genesis in medicine and clinical psychology, as noted recently (Chandola, et at., 2008; Greenberg, 2008; Mann, 2012); this can also be said for new studies on the role of the central nervous system (CNS) in BP regulation (Wyss, Carlson, 2001; Zubcevic, et al., 2011).

The role of stress in BP increase, first established at the beginning of the last century through psychophysiological research conducted by W. Cannon, I.P. Pavlov, H. Selye and G.F. Lang, today is once again being vigorously discussed and investigated with the application of modern diagnostic methods and a new documentary basis provided by contemporary science.

Ample studies show that the sympathetic nervous system (SNS) and the rennin-angiotensin-aldosterone system (RAAS) are basic physiological systems which sustain BP regulation. However, in spite of more than 100 years of research, it is still unclear whether recurrent short-term BP increases under emotional stress may lead to a constant BP increase, as is the role of SNS and RAAS in this process. Many specialists find it possible that occasional episodes of BP increase under stress in individuals with genetic and psychological predispositions may cause structural changes in the heart and blood vessels and result in constant HTN.

From the psychological point of view, the question of primary importance is that of which psychological features should distinguish a person who is subjected to enduring aggressive stressful situations. These may suggest a constant demand to comply with high and often excessive requirements every day for many years.

The purpose of this research is to conduct a theoretical analysis and empirical study of specific features of psychophysiological mechanisms of stress reactions in patients with HTN at work, as compared with essential HTN patients.

\section{The role of the sympathetic nervous system and rennin-angiotensin- aldosteron system in BP regulation under mental stress: historical and contemporary views}

Studies of the role of stress in the etiology and pathogenesis of HTN have a longstanding tradition. In the early works of W. Cannon and H. Selye, the role of SNS in emotion regulation and implementation of stress reaction was tested experimentally. Many inquiries into stress psychophysiology showed that the activation of the autonomic nervous system, in the first place its sympathetic branch, is the factor 
which triggers all stress-related physiological changes, including BP increase (Palatini, 1997; Wyss, Carlson, 2001; Kamarck, Lovallo, 2003; Zubcevic, et al., 2011).

In recent years the implication of the peripheral nervous system in long-term BP regulation and development of HTN complications has been revised. The unfavorable role of increased variability in $\mathrm{BP}$, a principal characteristic of stress-induced HTN, was proved. From a contemporary point of view, the medulla oblongata, hypothalamus and cerebral cortex are the main nervous centers contributing to BP regulation (Wyss, Carlson, 2001). New findings in the field of humoral and local $\mathrm{BP}$ regulation confirm the thesis that hormonal transmitting components of SNS are the most important homeostasis regulators responsible for stress resistance (Treiber, et al., 2003; Carlson, Wyss, 2011).

However, published data on SNS reaction to intellectual and emotional challenges in patients with HTN is quite ambiguous. In a number of studies, no reliable quantitative difference has been found between healthy individuals and patients with HTN in catecholamines (CA) excretion with urine in response to stress (Men'shikov, Makolkin, Bol'shakova, 1980; Rostrup, Westhein, Kjeldsen, 1993). Some researchers attribute CA increase to the reactive acceleration of its synthesis from dopamine in healthy individuals, and for patients with HTN, to the acceleration of dopamine production (Bell, 1987). Other authors would attribute the relative equality in the increase in concentration of adrenal medulla hormones under different hemodynamic effects to growth of sensitivity and activity of adrenoreceptors of the vascular wall in patients with HTN (Soltis, Field, 1984).

A considerable amount of work would also testify to a different adrenergic reaction in healthy individuals and in patients with HTN. For example, F.Z. Meerson evaluated the CA dynamics while informational tasks were solved by participants in time-limited conditions. He discovered that while initial adrenaline (A) and noradrenaline (NA) indices were relatively equal in both groups, patients with HTN reacted by A increase in blood plasma by $90 \%$, NA - by $107 \%$, while healthy individuals showed A increase by $80 \%$, NA - by $15 \%$ from the initial level (Meerson, Gurevich, 1981).

It is important to note that not every form of stress leads to identical hormonal and hemodynamic changes in participants. Many researchers believe that the peak of CA concentration coincides with a climax of graduated emotional strain. At the same time there is a certain contradiction in data provided by different investigations of dynamics of NA/A relation during the test. Most authors point out that healthy individuals, as well as patients with HTN, react with an increase in excretion of both A and NA. With all that, correlation of NA/A during stress tends to go down in the group of healthy participants. That is, stress in healthy individuals is brought about mostly by A; whereas patients with HTN are mostly characterized by NA increase, hence, NA/A correlation in these patients increases under stress (Meerson, Gurevich, 1981; Paran, Neumann, Cristal, 1992; Kurina, Schneider, Waite, 2004). However, some works suggest data of the opposite CA correlations in groups of healthy participants and patients with HTN (Georgiades, A., et al., 1997).

The role of SNS in HTN pathogenesis is estimated ambiguously. There are reports that NA and A excretion with urine recorded for patients with HTN is similar to indices for healthy individuals (Kushakovsky, 1977). Quite different results have been shown through research into CA concentration in blood plasma. An increase 
of NA level in blood plasma was detected in $43 \%$ of patients with HTN. This data is to some extent confirmed by the results obtained by J.R. Sowers and A. M. Richards, whose study into the daily rhythm of CA secretion and BP in HTN patients revealed a close correlation between NA content in blood plasma and BP indices (Richards, et al., 1986; Sowers, 1981).

The results of SNS activity studies in patients with HTN are equivocal. S.L. Lightman noted that among 22 world centers engaged in the study of CA metabolism under HTN, 7 laboratories obtained data on CA activation increase, while 11 suggest an absence of any significant changes, and another 4 provided data of its decrease (Lightman, et al., 1981). Such a variety of data may be accounted for by a number of reasons, for one thing, by the clinical heterogeneity of studied groups of patients.

The expansion of knowledge in HTN pathogenesis has led to a more scrupulous investigation of RAAS, which together with SNS form a humoral background of cardiovascular reactions. J.H. Laragh introduces a hypothesis of two types of HTN, one of which is characterized by increased renin activity in blood plasma (ARP), another HTN suggests low ARP, while BP remains high due to increased volume of circulating blood (Laragh, et al., 1972). However, the hypothesis was never confirmed, since there were contradictory data for the comparison of central and renal hemodynamics with ARP, especially at the initial stage of the disease, when depressor system is active enough and organic lesions of certain organs and vessels have not yet surfaced.

While RAAS implication in renovascular HTN has been quite well studied, the renin role in pathogenesis of essential HTN is still largely unclear. This becomes clear in counterpleading assessments of clinical data for HTN patients with low and high ARP. Thus, high ARP is accompanied by higher diastolic BP, most frequent and severe progress of hypertensive crises, proteinuria and retinopathy, and heart aches (Shhvacabaya, 1982). Conversely, crises and organic lesions are statistically rare in patients with low ARP (Laragh, et al., 1972). Other authors, contradicting Laragh, would emphasize a correlation with diastolic BP increase and an equal frequency of complications in patients with low ARP in comparison with patients with hyperreninemia.

Thus, analysis of published material leads us to conclude that SNS and RAAS are described as basic physiological systems, providing BP regulation. It is shown that RAAS and SNS are interactive systems with interactions on different levels: central, baroreceptor, adrenal, and level of postsynaptic $\mathrm{AT}_{1}$-receptors (Wyss, Carlson, 2001). In healthy people, the short-term effects of the two coordinated systems are directed at activation of powerful compensatory life-sustaining mechanisms. In this case, BP increase, heart rate (HR) growth, angiospasm, blood clotting growth, etc. have an adaptive effect. However, when stress reaction acquires a lingering character, the unfavorable consequences of long-term activation of these mechanisms become obvious.

Recent studies provide ample facts showing that the interaction of nervous (SNS) and humoral (RAAS) mechanisms of BP regulation under stress is one of the central mechanisms of psychophysiological maintenance not only for short-term $\mathrm{BP}$ increase under stress, but also for cases of chronic BP increase and the advance of HTN complications (Wyss, Carlson, 2001; Izzo, 2005; Joyner, Charkoudian, 
Wallin, 2008). It is necessary to emphasize the importance of purely psychological factors initiating hypertensive reactions as described.

There are several forms of HTN with a predominant increase of systolic BP (systolic BP) and/or SNS activation. Among them, the most interesting for verification of psychosomatic hypothesis is stress-induced HTN, including HTN at work.

\section{HTN at work: physiological and psychological aspects}

As we mentioned above, HTN at work is now one of the most frequent forms of stress-induced HTN.

The occurrence of HTN at work has been investigated in several projects. Thus, according to data obtained by J. Stork, HTN at work time was detected in 19\% of people with normal BP indices, displaying periodical ambulatory changes (Stork, et al.,1992). Recent studies indicate a growth in the frequency of this HTN form in the population (Molinari, Compare, Parati, 2006; Zubcevic, 2011). It most widely concerns people suffering from psychological stress in the workplace. Among the psychological features in patients with HTN at work, the following are emphasized: repressed disposition to anger caused by professional challenges; uncertainty in retaining their jobs; limited opportunities for promotion; high professional requirements with a low level of freedom in decision-making. The group of high-risk includes employees whose position is in the middle of social ladder, so they face pressure both from superiors and subordinates (Cottington, et al., 1986; Karasek, 1998; O'Donnell, et al., 2008). These patients are characterized by an intensive and enduring experience of negative emotions, which they are prone to conceal in their behavior under apprehensions of being rejected by others. The set of features in general corresponds to emotionality displayed by representatives of the so-called “Type D personality" (distressed personality) (Denollet, 2005).

Research has shown that stress-induced HTN is not a harmless phenomenon. Thus, BP level at work closely correlates with lesion of a target organ (in particular with hypertrophy of left ventricle myocardium), more so than with an ambulatory measured BP level or even night time BP level (Garvas, Garvas, 1999; and others). In the prospective research "Whitehall Study", conducted under the aegis of the WHO, a sample of 10308 managers revealed that restricted freedom in decisionmaking in professional activity (workers of low- and mid-level) is accompanied by a higher risk of developing ischemic heart disease, both in men and women (Chandola, et al., 2008; Nabi, et al., 3013). Employees suffering high emotional stress were characterized by evident BP increase, progressing with age, while other professional groups showed no such reactions. During prospective research covering 12 years, M. Julius showed that a repressed disposition to irritation in patients with HTN reliably correlates with growth in death rate. Healthy men with normal BP showed no such relationship (Julius, et al. 1986).

A generalized version of pathogenesis of HTN at work may be presented as follows: negatively experienced chronic stress along with genetic and acquired factors contributes in a way to the emergence and/or advance of HTN. In this case the increase of SNS activity serves as a central element of the described interaction. At this point, adrenal medulla releases predominantly A. It stimulates presynaptic $\beta_{2}-$ adrenoreceptors in sympathetic nerve endings, which in turn stimulate NA release. 
NA may become active in approaching $\alpha_{1}$-adrenoreceptors and $\beta_{1}$ - adrenoreceptors of a target organ (unstriated muscles of heart and blood vessels) and induce HTN. Frequent and long-term activation of sympathetic element leads to changes in the baroreceptor reflex, 'adjusting' BP to a higher level. Tone of vagus nerve decreases, while BP and HR increase.

The long-term increase of SNS activity may also lead to hyperinsulinemia, with its negative consequences (retention of renal excretion of sodium and water, infringement of cellular electrolyte transportation, development of blood vessels hypertrophy and emergence of metabolic syndrome). Stress reaction is accompanied by the release of adrenocorticotropic hormone and cortisol. Stress leads to a reduction in renal sodium excretion. Mental stress and saline factor may be mutually increasing.

Apart from the straight hypertensive effect, SNS stimulates RAAS. SNS and RAAS are closely related, since $\mathrm{AT}_{1}$ - receptors, mediating all the $\mathrm{A}_{\mathrm{II}}$ effects, are responsible for A and NA release in adrenal medulla. The sympathetic nerve, on the contrary, promotes renin formation in kidneys through A and NA. In consequence, an additive aggravation of pressor effects takes place, which creates further conditions for enduring progressive myocardium hypertrophy.

To summarize all that has been stated above, it should be noted that the most crucial question for understanding the etiology and pathogenesis of HTN at work is the following: what pathophisiological mechanisms stand behind the conversion of BP increase, emerging under mental stress, into a chronic state? Unfortunately, this question has no answer today, as s there is no answer to the question about the role of psychological factors in HTN pathogenesis.

\section{An empirical study of mental stress reactions in patients with HTN at work and patients with essential HTN}

The purpose of this empirical study is to inquire into the specifics of psychophysiological mechanisms of stress reaction in patients with HTN at work, as compared with essential HTN patients, and the revelation of psychological traits connected with particular characteristics of SNS and RAAS.

\subsection{Research methods and Participants}

The research was carried out with the application of methods of psychological experiment and psychological testing, and methods of physiological data registration.

A stressful situation was created experimentally, employing the procedure of aspiration level (AL) research. A situation was set up that induced a state of mental tension. In the course of the experiment, participants were asked to solve 12 tasks. As stimulating material, Raven's Progressive Matrices, series D and E, were used. The selection of the most difficult, almost unsolvable tasks was stipulated by the purpose of the experiment: to set up a stressful situation. In a preliminary interview, a motivated attitude toward the work was encouraged in the participants, and the experiment was presented as a test of expertise. A time limit was set for task fulfillment. Before and after the experiment participants' level of state anxiety (SA) (the Spielberger SA Inventory), and physiological indices (BP reaction, CA level 
in urine, rennin and $A_{I}$ level in blood plasma) were assessed. In the course of the experiment features of AL and characteristics of participants' nonverbal behavior were estimated.

Statistical processing of the data was conducted with the application of various methods: calculation of mean values and the standard deviation; calculation of the certainty of distinctions between samples based on indicators of the probability of distinctions between indicators (Student's t-test); detection of correlations among investigated features in groups of participants, employing the method of calculation of Spearman's rank correlation coefficient $\left(r_{s}\right)$, and the Cluster analysis method.

The study involved 170 patients with HTN, stage II, and 82 healthy individuals. Among the HTN patients, 85 participants with HTN at work (mean age was $44.7 \pm 4.3$ years) were singled out (the first group). This group comprised patients whose BP on working days was statistically higher than their BP on days off (according to results of the ambulatory 48-hours BP monitoring). The second group comprised 85 patients with essential HTN, with a mean age of $47.4 \pm 4.5$ years. The mean age of healthy participants was $44.9 \pm 3.1$ years.

\subsection{Results}

\subsubsection{Research in dynamics of physiological indices and anxiety level of patients} with HTN and healthy individuals in the course of the experiment

BP data analysis in patients with HTN and healthy individuals shows that average BP indices before the experiment are increased in patients with HTN in comparison with the norm. After the experiment, an increase of BP is detected in both groups, however the increase of systolic BP in patients with HTN is statistically reliable $(\mathrm{p}<0.05)$ (Table 1$)$.

Table 1. Average blood pressure indices in HTN patients and in healthy individuals before and after the experiment $(\mathrm{mmHg})$

\begin{tabular}{lcc}
\hline \multicolumn{1}{c}{ Blood pressure indices } & $\begin{array}{c}\text { Patients with HTN, } \\
\mathbf{n}=\mathbf{1 7 0}(\mathbf{M e} \pm \text { SD) }\end{array}$ & $\begin{array}{c}\text { Healthy individuals, } \\
\mathbf{n = 8 2}(\mathbf{M e} \pm \text { SD) }\end{array}$ \\
\hline Systolic BP before the experiment & $141.6 \pm 4.1^{*}$ & $127.0 \pm 3.5$ \\
Systolic BP after the experiment & $155.5 \pm 4.3^{*}$ & $130.0 \pm 1.3$ \\
$\Delta$ Systolic BP & $13.9 \pm 1.3^{*}$ & $3.0 \pm 0.8$ \\
Diastolic BP before the experiment & $94.6 \pm 3.1^{\star}$ & $82.7 \pm 3$ \\
Diastolic BP after the experiment & $96.1 \pm 2.5^{*}$ & $84.8 \pm 2.9$ \\
$\Delta$ Diastolic BP & $1.5 \pm 0.8$ & $2.1 \pm 0.9$ \\
\hline
\end{tabular}

Note. Me - mean; SD - standard deviation. ${ }^{*}$ Differences between the groups are reliable $(\mathrm{p}<0.05)$.

BP indices in patients with HTN from the first (HTN at work) and second (essential HTN) groups before and after the experiment are presented in Table 2. No reliable differences in BP indices between the mentioned groups before and after the experiment were recorded. However, after the experiment the growth of systolic BP indices in the first group was reliable higher $(\mathrm{p}<0.05)$ than in the second group (16.1 \pm 1.9 and $4,1 \pm 0,7 \mathrm{mmHg}$ respectively). 
Table 2. Average blood pressure indices in the compared groups of HTN patients before and after the experiment $(\mathrm{mmHg})$

\begin{tabular}{lcc}
\hline \multicolumn{1}{c}{ Blood pressure indices } & $\begin{array}{c}\text { Patients with HTN at work, } \\
\mathbf{n = 8 5}(\mathbf{M e} \pm \mathbf{S D})\end{array}$ & $\begin{array}{c}\text { Patients with essential } \\
\text { HTN, } \mathbf{n}=\mathbf{8 5}(\mathbf{M e} \pm \mathbf{S D})\end{array}$ \\
\hline Systolic BP before the experiment & $141.0 \pm 3.5$ & $149.0 \pm 3.8$ \\
Systolic BP after the experiment & $157.1 \pm 4.1$ & $153.1 \pm 4.0$ \\
$\Delta$ Systolic BP & $16.1 \pm 1.9^{*}$ & $4.1 \pm 0.7$ \\
Diastolic BP before the experiment & $92.8 \pm 2.0$ & $98.9 \pm 2.4$ \\
Diastolic BP after the experiment & $97.3 \pm 2.9$ & $101.3 \pm 2.8$ \\
$\Delta$ Diastolic BP & $4.5 \pm 0.7$ & $2.4 \pm 0.5$ \\
\hline
\end{tabular}

Note. Me - mean; SD - standard deviation. ${ }^{*}$ Differences between the groups are reliable $(\mathrm{p}<0.05)$.

A comparison of CA levels in urine and renin and $\mathrm{A}_{1}$ in blood plasma in patients with HTN from the first and second groups, before and after the experiment, showed that patients from the first group have an initially reliably lower level of $A$ and NA in blood than patients from the second group, and that levels of renin and $A_{1}$ are comparable. In the course of the experiment, patients from the second group displayed a reliable increase in all four analyzed indices, as the second group showed a reliable decrease. Analysis of the data received during the experiment allows us to note the paradoxicality of reactions to stress in patients with HTN at work (Table 3).

Table 3. Levels of catecholamines in urine, renin, and angiotensin 1 in blood plasma in the compare groups of HTN patients before and after the experiment

\begin{tabular}{llcc}
\hline \multicolumn{2}{l}{ Parameters } & $\begin{array}{c}\text { Patients with HTN } \\
\text { at work, } \mathbf{n}=\mathbf{8 5} \\
(\mathbf{M e} \pm \text { SD })\end{array}$ & $\begin{array}{c}\text { Patients with } \\
\text { essential HTN, n=85 } \\
(\mathbf{M e} \pm \text { SD) }\end{array}$ \\
\hline Adrenaline, nmol/s & before the experiment & $81.7 \pm 0.2$ & $119.8 \pm 0.2 \#$ \\
after the experiment & $54.3 \pm 0.2^{*}$ & $211.4 \pm 0.2^{*}$ \\
Noradrenaline, $\mathrm{nmol} / \mathrm{s}$ & before the experiment & $151.6 \pm 0.3$ & $182.1 \pm 0.3 \#$ \\
& after the experiment & $138.6 \pm 0.3^{*}$ & $329.2 \pm 0.3^{*}$ \\
Renin, $(\mathrm{ngr} / \mathrm{ml}) / \mathrm{s}$ & before the experiment & $1.04 \pm 0.21$ & $0.86 \pm 0.21$ \\
& after the experiment & $0.84 \pm 0.01^{*}$ & $0.96 \pm 0.01^{*}$ \\
Angiotensin $1,(\mathrm{ngr} / \mathrm{ml}) / \mathrm{s}$ & before the experiment & $1.14 \pm 0.13$ & $1.26 \pm 0.09$ \\
& After the experiment & $0.96 \pm 0.03^{*}$ & $1.35 \pm 0.03^{*}$ \\
\hline
\end{tabular}

Note. $\mathrm{Me}-$ mean; $\mathrm{SD}-$ standard deviation. ${ }^{\star}$ Differences in the data before and after the experiment are reliable $(\mathrm{p}<0.05)$. \# Differences between the groups are reliable $(\mathrm{p}<0.05)$.

Data analysis of the Spielberger SA Inventory shows an absence of reliable statistical differences both between and inside the groups before and after the experiment. However, the value of the standard deviation in the HTN group indicates a considerable SA data spread both before and after the experiment (Table 4). 
Table 4. Average values of state anxiety level in HTN patients and in healthy individuals before and after the experiment (points)

\begin{tabular}{lcc}
\hline \multicolumn{1}{c}{ State anxiety level } & $\begin{array}{c}\text { Patients with HTN, } \mathbf{n}=\mathbf{1 7 0} \\
(\mathbf{M e} \pm \text { SD) }\end{array}$ & $\begin{array}{c}\text { Healthy individuals, } \mathbf{n}=\mathbf{8 2} \\
(\mathbf{M e} \pm \mathbf{S D})\end{array}$ \\
\hline SA before the experiment & $41.1 \pm 3.6$ & $39.6 \pm 2.8$ \\
SA after the experiment & $43.3 \pm 4.8$ & $41.8 \pm 2.9$ \\
$\Delta$ SA & $2.2 \pm 0.3$ & $2.2 \pm 0.2$ \\
\hline
\end{tabular}

Note. $\mathrm{Me}$ - mean; SD - standard deviation. There are no significant differences between the groups in SA.

A comparison of SA level in patients with HTN from the first and second groups showed that qualitative changes of SA level before and after the experiment were comparable in both groups. However, SA level in patients with HTN at work initially was reliably higher, hence the data after the experiment is also reliably higher in comparison with the second group (Table 5).

Table 5. Average indices of state anxiety level in the compare groups of HTN patients before and after the experiment (points)

\begin{tabular}{lcc}
\hline \multicolumn{1}{c}{ State anxiety level } & $\begin{array}{c}\text { Patients with } \mathbf{H T N} \text { at work, } \\
\mathbf{n = 8 5}(\mathbf{M e} \pm \mathbf{S D})\end{array}$ & $\begin{array}{c}\text { Patients with essential HTN, } \\
\mathbf{n = 8 5}(\mathbf{M e} \pm \mathbf{S D})\end{array}$ \\
\hline SA before the experiment & $42,8 \pm 3,6^{*}$ & $37,0 \pm 2,3$ \\
SA after the experiment & $45,2 \pm 2,9^{*}$ & $38,3 \pm 2,0$ \\
$\Delta$ SA & $2,4 \pm 0,5$ & $1,3 \pm 0,2$ \\
\hline
\end{tabular}

Note. Me - mean; SD - standard deviation. ${ }^{\star}$ Differences between the groups are reliable $(\mathrm{p}<0.05)$.

Moreover, we assessed qualitative changes (increase or decrease) in reactive anxiety in the course of experiment. It eventually turned out that the frequency of negative change in SA indices after the experiment is reliably higher $(\mathrm{p}<0.05)$ in the group of patients with HTN than in healthy individuals, forming $47.7 \%$. It presumably implies repression of anxiety and other emotions by patients at the moment of stress, as BP increase is reliable $(\mathrm{p}<0.05)$.

Table 6. Frequency of positive and negative changes of state anxiety level in the compare groups of HTN patients before and after the experiment $(\%)$

\begin{tabular}{|c|c|c|c|c|}
\hline \multirow{2}{*}{$\begin{array}{l}\text { Pattern of SA change } \\
\text { after experiment }\end{array}$} & \multicolumn{2}{|c|}{$\begin{array}{l}\text { Patients with HTN at } \\
\text { work, } n=85\end{array}$} & \multicolumn{2}{|c|}{$\begin{array}{l}\text { Patients with essential } \\
\text { HTN, } n=85\end{array}$} \\
\hline & Absolute value & $\%$ & Absolute value & $\%$ \\
\hline $\begin{array}{l}\text { Anxiety increases after experiment, } \\
\mathrm{SA}_{2}>\mathrm{SA}_{1}\end{array}$ & $31^{*}$ & $36.5 \%{ }^{*}$ & 58 & $68.2 \%$ \\
\hline $\begin{array}{l}\text { Anxiety decreases after experiment, } \\
\mathrm{SA}_{2}<\mathrm{SA}_{1}\end{array}$ & $54^{\star}$ & $63.5 \%{ }^{*}$ & 27 & $31.8 \%$ \\
\hline
\end{tabular}

Note. ${ }^{*}$ Differences between the groups are reliable $(\mathrm{p}<0.05)$. 
Comparative analysis of the frequency of positive and negative SA changes before and after the experiment in patients with HTN from the first and second groups showed that in the first group , SA decrease after the experiment $\left(\mathrm{SA}_{2}<\mathrm{SA}_{1}\right)$ is reliably more frequent $(\mathrm{p}<0.05)$, than in the second group $(63.5 \%$ and $31.8 \%$, respectively). Patients from the second group are characterized by reliably more frequent $(\mathrm{p}<0.05)$ increases of $\mathrm{SA}$ indices $\left(\mathrm{SA}_{2}>\mathrm{SA}_{1}\right)$ after the experiment (Table 6).

Thus, on the basis of data analysis we may conclude that patients with HTN in general differ from healthy individuals by more significant physiological changes arising in the situation of experimental stress modeling. It is shown that patients with stress-induced HTN demonstrate more significant stress reactions, which in certain cases appear paradoxical. It should also be noted that the obtained results testify to the internal heterogeneity of each of the compared groups of HTN patients, which is reflected in the physiological indices.

\subsubsection{Study of aspiration level features and nonverbal behavior of patients with} HTN and healthy individuals in the course of experiment

Analysis of participants' AL features showed that healthy individuals in our study demonstrate mainly medium AL, rather stable and adequate. In the course of the experiment they show more flexible reactions to success/failure, and introduce corrections into their strategy for picking up the next task with regard to effectiveness of the previous one (Table 7).

Table 7. Frequency of aspiration level characteristics in the compare groups of HTN patients and in healthy individuals (\%)

\begin{tabular}{llccc}
\hline \multicolumn{2}{c}{$\begin{array}{c}\text { Aspiration level } \\
\text { characteristics }\end{array}$} & $\begin{array}{c}\text { Patients with HTN } \\
\text { at work, } \mathbf{n = 8 5}\end{array}$ & $\begin{array}{c}\text { Patients with } \\
\text { essential HTN, } \mathbf{n = 8 5}\end{array}$ & $\begin{array}{c}\text { Healthy } \\
\text { individuals, } \mathbf{n = 8 2}\end{array}$ \\
\hline Height & High AL & $71.7^{\star}$ & $75.3^{*}$ & 39.0 \\
& Middle AL & $16.5^{\star}$ & $16.5^{\star}$ & 50.0 \\
\multirow{6}{*}{ Stability } & Low AL & 11.8 & 8.2 & 11.0 \\
& Stable AL & $43.5^{\star} \#$ & 60.0 & 69.5 \\
& Unstable AL & $56.5^{\star} \#$ & 40.0 & 30.5 \\
Adequacy & Adequate AL & $30.6^{\star} \#$ & $43.5^{*}$ & 59.8 \\
& Inadequate AL & $69.4^{\star} \#$ & $56.5^{*}$ & 40.2 \\
\hline
\end{tabular}

Note. ${ }^{*}$ Differences are reliable in comparison with the group of healthy individuals $(p<0.05)$. \# Differences between the first and second groups of patients with HTN are reliable $(\mathrm{p}<0.05)$.

The group of patients with HTN had different AL results. Differences were observed for three points: height, stability, and adequacy. In the height profile of AL, HTN patients were superior to healthy subjects. Inadequacy $(78.3 \%)$ and instability $(40.1 \%)$ profiles of AL appeared reliably more frequently $(\mathrm{p}<0.05)$. As it is shown, patients with HTN at work had a reliably more unstable $(56.5 \%)$ and inadequate $(69.4 \%)$ AL compared with the second group $(\mathrm{p}<0.05)$. According to the data analysis, patients from the second group in the parameters "stability" and "adequacy" are closer to healthy individuals, than patients with stress-induced HTN (Table 7). 
Analysis of participants' nonverbal behavior showed that the group of patients with HTN differed from healthy participants by a greater amount of gestures, more frequent changes in voice, and higher points in the general factor of nonverbal behavior $(\mathrm{p}<0.05)$ (Table 8$)$.

Table 8. Average values of nonverbal behaviors in HTN patients and in healthy individuals (points)

\begin{tabular}{lcc}
\hline Nonverbal behaviors & $\begin{array}{c}\text { Patients with HTN, } \\
\mathbf{n = 1 7 0}(\mathbf{M e} \pm \text { SD })\end{array}$ & $\begin{array}{c}\text { Healthy individuals, } \\
\mathbf{n = 8 2}(\mathbf{M e} \pm \text { SD })\end{array}$ \\
\hline Gestures & $20.5 \pm 1.6^{*}$ & $15.5 \pm 1.5$ \\
Poses & $7.4 \pm 1.3$ & $6.0 \pm 0.8$ \\
Facial expressions & $12.1 \pm 0.9$ & $13.4 \pm 2.2$ \\
Tone of voice & $9.0 \pm 1.2^{*}$ & $4.4 \pm 0.8$ \\
General index of nonverbal & $49.0 \pm 1.2^{*}$ & $39.3 \pm 3.1$ \\
activity & & \\
\hline
\end{tabular}

Note. $\mathrm{Me}-$ mean; SD - standard deviation. ${ }^{*}$ Differences between the groups are reliable $(\mathrm{p}<0.05)$.

Analysis of nonverbal behavior in the compared groups of patients with HTN showed that patients from the first group employ reliably less gestures and changes of poses $(p<0.05)$, but display more vigorous facial expressions and changes in voice tone $(\mathrm{p}<0.05)$, in comparison with the second group (Table 9).

Table 9. Average values of nonverbal behaviors in the compare groups of HTN patients and in healthy individuals (points)

\begin{tabular}{lccc}
\hline Nonverbal behaviors & $\begin{array}{c}\text { Patients with HTN } \\
\text { at work, } \mathbf{n}=\mathbf{8 5} \\
(\mathbf{M e} \pm \mathbf{S D})\end{array}$ & $\begin{array}{c}\text { Patients with } \\
\text { essential HTN, } \\
\mathbf{n = 8 5}(\mathbf{M e} \pm \text { SD) }\end{array}$ & $\begin{array}{c}\text { Healthy } \\
\text { individuals, } \\
\mathbf{n = 8 2}(\mathbf{M e} \pm \text { SD) }\end{array}$ \\
\hline Gestures & $18.3 \pm 2.8 \#$ & $21.6 \pm 2.9^{*}$ & $15.5 \pm 1.5$ \\
Poses & $7.3 \pm 2.6 \#$ & $10.1 \pm 2.6^{*}$ & $6.0 \pm 0.8$ \\
Facial expressions & $18.3 \pm 2.7^{\star} \#$ & $9.4 \pm 1.1$ & $13.4 \pm 2.2$ \\
Tone of voice & $12.9 \pm 1.3^{\star} \#$ & $7.2 \pm 1.2^{*}$ & $4.4 \pm 0.8$ \\
General index of nonverbal & $56.8 \pm 5.2^{*}$ & $48.3 \pm 4.1^{*}$ & $39.3 \pm 3.1$ \\
activity & & & \\
\hline
\end{tabular}

Note. Me - mean; SD - standard deviation. ${ }^{\star}$ Differences are reliable in comparison with the group of healthy individuals $(\mathrm{p}<0.05)$. \# Differences between the first and second groups of patients with HTN are reliable $(\mathrm{p}<0.05)$.

Thus, analysis of the results from this stage of research allow us to conclude that patients with HTN differ from healthy individuals by reliably higher but inadequate and unstable aspiration levels, and higher indices in all estimated parameters of nonverbal behavior. This leads us to assume that the group of patients with $\mathrm{HTN}$ at work differs in AL indices not only from healthy individuals but also from patients with essential HTN. 


\subsubsection{Analysis and discussion of results}

Analysis of the received results showed that within our research, employing experimental stress modeling, a state of emotional tension was formed in practically all the patients with HTN. This fact is confirmed by BP increase in all the patients with HTN over the course of the experiment, reliably higher than in healthy individuals, and also by significant anxiety in behavior, estimated by a complex of parameters of nonverbal behavior.

However, some patients with HTN were characterized not by an increase (which is regarded as the norm for a stressful reaction), but by a decrease of indices of all measured biochemical parameters, as well as by a decrease of anxiety level (according to data from Spielberger SA Inventory). Besides, patients with a decrease of biochemical indices in the course of stress-modeling were also characterized by initially lower indices of $\mathrm{A}$ and NA in urine, and renin and $\mathrm{A}_{\mathrm{I}}$ in blood plasma. This may be explained by the absence of essential biochemical "pre-race readiness", which is extremely important for entering a stressful situation and efficiently coping with it. It may also be an indicator of a long-endured stressful state of the patients. That is, what the patients display is not a "fight or flight readiness" with mobilization of organism resources, but a state of exhaustion of adaptation reserve. It should be noted that few studies have observed a decrease of biochemical parameters under stress in patients with HTN (Lindvall, et al., 1991).

It is necessary to point out that in our research, the presence of reliable $(\mathrm{p}<0.01)$ positive correlations was found between the decrease of indices in the Spielberger SA scale and decrease of biochemical indices in the course of the experiment. This phenomenon is reliably more frequent in the group of patients with HTN at work. The group revealed reliable $(\mathrm{p}<0.01)$ negative correlations between the high frequency of systolic BP increase and the decrease of biochemical indices ( $A$ and NA in urine, renin and $A_{I}$ in blood plasma); and also reliable $(\mathrm{p}<0.01)$ negative correlations between the high frequency of BP increase and the decrease of anxiety level. In the group of patients with essential HTN, such regularity was not found.

The described facts, we assume, confirm the hypothesis on the state of psychophysiological exhaustion, diagnosed in some patients with HTN through a complex of physiological and psychological characteristics. Besides, this data may be considered as indirect evidence that a stressful state with significant biochemical changes found in some patients with HTN is chronic.

Furthermore, cluster analysis of the data confirmed the hypothesis of the general heterogeneity of patients with HTN, as well as the internal heterogeneity of the compared groups of patients with HTN. Three well-interpreted clusters were statistically marked out; they embrace psychological, physiological and behavioral parameters, which made it possible to describe 3 subgroups inside the groups of patients with HTN:

1. Patients with openly anxious reaction type (91 patients, 53.5\% of all participants with HTN). Patients from this group are characterized by a significant increase of SA level in the course of experiment, open emotion expression, a rich variety of behavioral exposure accompanied by a slight BP growth and increase of $A, N A$, renin and $A_{I}$ level in the course of experiment. 
2. Patients with excessive emotion repression (70 people, $41.2 \%$ of participants with HTN). They showed a significant growth of systolic BP level, initially lower A and NA levels, and a decrease in the course of experiment of all measured biochemical parameters; a decrease of SA level, instability and inadequacy of AL. They were characterized by outwardly more quiet behavior and a lower number of poses and gestures, but more varied facial expressions and changes in voice tone.

3. Patients, who differ from the above-mentioned groups by moderate changes in physiological and psychological parameters under stress with optimal indices of emotion control, which brings them closer to the group of healthy individuals ( 9 patients, $5.3 \%$ of participants with HTN).

Statistical data analysis showed that in the group of patients with HTN at work, a phenomenon of excessive emotional repression was detected in $63 \%$ of cases; an openly anxious type of stress reaction was detected in $37 \%$. There were no patients with an adaptive reaction to stress in this group.

Most patients with essential HTN without a BP increase on working days show the openly anxious type of reaction (69\% of cases). The repressive type of reaction is present in $20 \%$ of cases; and that of adaptive - in $10 \%$ of patients.

There is an assumption prevailing in contemporary publications that emotion repression serves as a leading psychological factor of psychosomatic syndrome genesis in patients with HTN. The qualitative data analysis brings us to conclude that this cannot be accounted for pathogenesis of all HTN forms. The emotion repression phenomenon, according to our data, is particularly specific for patients with HTN at work.

For patients with essential HTN, open expression of emotions with a lack of regulation and control of emotions is more typical. However, a low percentage of patients in this group is characterized by normal psychophysiological reactions. Data interpretation suggests that BP increase at least in some of patients with essential HTN without BP increase at work is only marginally mediated by psychological factors. However, verification of this hypothesis requires additional investigation. The group of patients with open anxiety expression and a lack of emotion regulation, in our view, is interesting for psychological study. Our results enable us to assume that these patients are characterized by marginal cognitive mediation of emotional processes. This is the reason for the "explosive character" of their emotional reactions. However, this hypothesis also requires special verification.

The results of this research not only extend the scientific conceptualization of the nature of HTN, but also contribute to the formulation of new questions, which are extremely important for the organization of further studies in clinical psychology (Han, et al., 2009; Veraksa, et al., 2012; Pöppel, Wagner, 2012; Pöppel, et al., 2013; Mezzich, et al., 2013; Zinchenko, Pervichko, Martynov, 2013).

\section{Conclusions and implications}

1. In patients with HTN in a situation of experimental stress modeling, a complex of physiological and psychological features was defined, which differ them from healthy individuals. During mental stress in the group of patients with HTN, a reliably greater growth of systolic BP is registered in comparison with healthy 
individuals (in average by 14 and $3 \mathrm{mmHg}$ respectively). AL of these patients is characterized by reliably greater height, inadequacy and instability; and nonverbal behavior - by a reliably greater amount of gestures and frequent changes of voice tone in comparison with healthy individuals.

2. In the situation of mental stress modeling, the group of patients with HTN is heterogenic in its physiological and psychological features: $53.5 \%$ of patients are characterized by open anxiety expression and lack of regulation and control of emotions, $41.2 \%$ of patients display dominant signs of emotion repression, and only $5.3 \%$ of participants demonstrate optimal stress reactions.

3. The group of patients with HTN at work, in comparison with patients from the second HTN group, is characterized by a reliably greater BP growth (on average by 16 and $4 \mathrm{mmHg}$ respectively) as a response to mental stress. They show initially reliably low $\mathrm{A}$ and NA level and decrease of A, NA renin and $\mathrm{A}_{\mathrm{I}}$ levels during the experiment. They are characterized by an absence of SA increase under mental stress, more frequent AL inadequacy (69.4\%) and instability (56.5\%). Their behavior during the experiment was marked by a limited repertory of gestures and poses, and more vigorous facial expressions and frequent changes in voice tone, as compared with patients with equal or lower BP level on working days than on days off.

4. The received results testify that $63 \%$ of patients with HTN at work in our research show a state of chronic stress and psychophysiological exhaustion. All these patients are characterized by the use of the mechanism of emotion repression as a main regulator of emotional state and behavior in stressful situations. With all the facts mentioned above, we may conclude that emotion repression may be considered as an important pathogenesis factor of psychosomatic syndrome genesis in patients with HTN at work, as distinct from patients with essential HTN.

5. These results extend the understanding of the etiology and pathogenesis of HTN, encouraging a more accurate identification of strategies for medical and psychological treatment of patients with HTN, as well as healthy persons who are in stressful situations.

\section{References}

Bell, C. (1987). Endogenous renal dopamine and control of blood pressure. Clin. Exp. Hypertension, A9 (5/6), 955-975. doi: 10.3109/10641968709161459

Carlson, S.H., \& Wyss, J.M. (2011). Mechanisms Underlying Hypertension and Obesity: A Melanocortin Linkage in the Brain. Hypertension, 57, 375-376. doi: 10.1161/ HYPERTENSIONAHA.110.161729

Chandola, T., Britton, A., Brunner, E., Hemingway, H., Malik, M., Kumari, M., Badrick, E., Kivimaki, M., \& Marmot, M. (2008). Work stress and coronary heart disease: what are the mechanisms? European Heart Journal, 29(5), 640-648. doi:10.1093/eurheartj/ehm584

Cottington, E.M., Matthews, K.A., Talbott, E., \& Kuller, L. H. (1986). Occupational stress, suppressed anger and hypertension. Psychosom. Med., 48(3/4), 249-260.

Denollet, J. (2005). DS14: standard assessment of negative affectivity, social inhibition, and Type D personality. Psychosom. Med., 67(1), 89-97. doi: 10.1097/01.psy.0000149256.81953.49 
Garvas, I., \& Garvas, H. (1999). Effects of eprosortan versus enelepril in hipertensive patients on the renin-angiotensine-aldosteron system and safety parameters: result from a 26-week, double-blind, multicentre study. Cur. Med. Res. Opin., 15(1), 13-24.

Georgiades, A., Lemne, C., De Faire, U., Lindvall, K., \& Fredrikson, M. (1997). Stress-induced blood pressure measurements predict left ventricular mass over three years among borderline hypertensive men. European Journal of Clinical Investigation, 27, 733-737. doi: 10.1046/ j.1365-2362.1997.1800729.x

Greenberg, J. S. (2008). Comprehensive Stress Management, 10th ed. Boston: McGraw-Hill.

Han, S., Fan, Y., Xu, X., Qin, J., Wu, B., Wang, X., Aglioti, S. M., \& Mao, L. (2009). Empathic neural responses to others' pain are modulated by emotional contexts. Human Brain Mapping, 30, 3227-3237. doi: 10.1002/hbm.20742

Izzo, J. L. Jr. (2005). The sympathetic nervous system in acute and chronic blood pressure elevation. In S. Oparil and M.A. Weber (Eds.), Hypertension: A Compantion to Brenner and Rector's the Kidney, 2nd Ed. (pp. 60-76). Philadelphia, Pa: Elsevier.

Joyner, M. J., Charkoudian, N., \& Wallin, B. G. (2008). A sympathetic view of the sympathetic nervous system and human blood pressure regulation. Experimental Physiology, 93(6), 715724. doi: 10.1113/expphysiol.2007.039545

Julius, M., Harburg, E., Cottington, E. M., \& Johnson, E. H. (1986). Anger- coping types, blood pressure, and all- cause mortality: a follow-up in Tecumseh, Michigan (1971-1983). Am. J. Epidemiologie, 124, 220-233.

Kamarck, T. W. \& Lovallo, W. (2003). Cardiovascular reactivity to psychological challenge: Conceptual and measurement considerations. Psychosomatic Medicine, 65, 9-21. doi: 10.1097/01.PSY.0000030390.34416.3E

Karasek, R. (1998). Demand/Control Model: A social, emotional, and physiological approach to stress risk and acrive behaviour development. In J. M. Stellman (Ed.) Encyclopaedia of occupational health and safety (pp. 34.6-34.14). Geneva: International Labour Office.

Kurina, L. M., Schneider, B., \& Waite, L. J. (2004). Stress, symptoms of depression and anxiety, and cortisol patterns in working parents. Stress and Health, 20, 53-63. doi: 10.1002/ smi.998

Kushakovsky, M. S. (1977). Gipertonicheskaja bolezn' [Essential hypertension]. Moscow: Medicina.

Laragh, J. H., Baer, L., Brunner, H. R., Biihler, F. R., Sealey, J. E. \& Vaughan, E.D. (1972). Renin, angiotensin and aldosterone system in pathogenesis and management of hypertensive vascular disease. Amer. J. Med., 52, 633-652. doi: 10.1016/0002-9343(72)90054-X

Light, K. C. (2000). Environmental and psychosocial stress in hypertension onset and progression. In S. Oparil, M. Weber (Eds.), Hypertension, pp. 59-70. Philadelphia, Pa: W. B. Saunders.

Lightman, S. L., James, V. H. T., Linsell, C., Mullen, P. E., Peart, W. S., \& Sever, P. S. (1981). Studies of diurnal changes in plasma rennin activity and plasma noradrenaline, aldosterone and cortisol concentrations in man. Clin. Endocrinol., 14, 213-223. doi: 10.1111/j.13652265.1981.tb00190.x

Lindvall, K., Kahan, T., de Faire, V., Ostergren, J., \& Hjemdahl, P. (1991). Stress-induced changes in dlood pressure and left ventricular function in mild hypertension. Clin. Cardiol., 14(2), 125-132. doi: 10.1002/clc.4960140208

Mann, S. J. (2012). Psychosomatic Research in Hypertension: The Lack of Impact of Decades of Research and New Directions to Consider. The Journal of Clinical Hypertension, 14(10), 657-664. doi: 10.1111/j.1751-7176.2012.00686.x

Meerson, F. Z., \& Gurevich, M. I. (1981). Narushenija sokratitel'noj funkcii gladkoj myshcs sosudistoj stenki pod vlijaniem jemocional'no-bolevogo stressa [Violations of the contractile 
function of smooth muscle of the vascular wall under the influence of emotional and painful stress]. Kardiologiya [Cardiology], 8, 108-115.

Men'shikov, V. V., Makolkin, V. I., \& Bol'shakova, T. F. (1980). Nejrojendokrinnaja reguljacija $\mathrm{u}$ bol'nyh NCD [Neuroendocrine regulation in patients with neurocirculatory dystonia]. Kardiologiya [Cardiology], 20(11), 23-28.

Mezzich, J. E., Zinchenko, Yu. P., Krasnov, V. N., Pervichko, E. I., \& Kulygina, M. A. (2013). Person-centered approaches in medicine: clinical tasks, psychological paradigms, and postnonclassic perspective. Psychology in Russia: State of the Art, 6 (1), 95-109. doi: 10.11621/ pir.2013.0109

Molinari, E., Compare, A., \& Parati, G. (2006). Clinical Psychology and Heart Disease. New York: Springer-Verlag. doi: 10.1007/978-88-470-0378-1

Nabi, H., Kivimäki, M., Batty, G.D., Shipley, M. J., Britton, F., Brunner, E. J., Vahtera, J., Lemogne, C., Elbaz, A., \& Singh-Manoux, A. (2013). Increased risk of coronary heart disease among individuals reporting adverse impact of stress on their health: the Whitehall II prospective cohort study. European Heart Journal. Retrieved from http://eurheartj.oxfordjournals.org/ by (June 27, 2013). doi:10.1093/eurheartj/eht216

O’Donnell, K., Brydon, L., Wright, C., \& Steptoe, A. (2008). Self-esteem levels and cardiovascular and inflammatory responses to acute stress. Brain, Behavior, and Immunity, 22(8), 1241-1247. doi: 10.1016/j.bbi.2008.06.012

Palatini, P., Casiglia, E., Pauletto, P., Staessen, J., Kacicroti, N., \& Julius, S. (1997). Relationship of tachycardia with high blood pressure and metabolic abnormalities. A study with mixture analysis in three populations. Hypertension, 30(5), 1267-73. doi: 10.1161/01. HYP.30.5.1267

Paran, E., Neumann, L., \& Cristal, N. (1992). Effects of mental and physical stress on plasma catecholamine levels before and after $B$-adrenoreceptor blocker treatment. Eur. J. Clin. Pharmacol., 43(1), 11-15. doi: 10.1007/BF02280747

Pöppel, E., \& Wagner, B. (2012). Von Natur aus kreativ [On nature of creativity]. München: Hanser-Verlag. doi: 10.3139/9783446432864

Pöppel, E., Avram, M., Bao, Y., Graupmann, V., Gutyrchik, E., Lutz, A., Park, M., Reiser, M., Russell, E., Silveira, S., Smigielski, L., Szymanski, C., \& Zaytseva, Y. (2013). Sensory Processing of Art as a Unique Window into Cognitive Mechanisms: Evidence from Behavioral Experiments and fMRI Studies. Procedia-Social and Behavioral Sciences, 86, 10-17. doi: 10.1016/j. sbspro.2013.08.517

Richards, A. M., Nicholls, M. G., Espiner, E.A., Ikram, H., Cullens, M., \& Hinton, D. (1986). Diurnal patterns of blood pressure, heart rate and vasoactive hormones in normal man. Clin. Exp. Hypertens., A8, 153-166. doi: 10.3109/10641968609074769

Rostrup, M., Westhein, A., \& Kjeldsen, S. T. (1993). Cardiovascular reactivity, coronary risk factors, and sympathetic activity in young men. Hypertension, 22(6), 891-899. doi: 10.1161/01. HYP.22.6.891

Shhvacabaya, I. K. (1982). Gipertonicheskaja bolezn' [Essential hypertension]. In E.I. Chazov (Ed.) Rukovodstvo po kardiologii [Manual in Cardiology] (pp. 5-64). Moscow: Medicina.

Soltis, E. E., \& Field, E. P. (1984). Effect of high blood pressure stress on vascular adrenergic responsiveness in the spontaneously hypertensive rat. Clin. Exp. Hypertens. Theory and practice, A6 (2), 1237-1255. doi: 10.3109/10641968409039594

Sowers, J. R. (1981). Dopaminergic control of circadian norepinephrine levels in patients with essential hypertension. J. Clin. Endocrinol. Metab., 53, 1133-1137. doi: 10.1210/jcem-53-61133 
Stork, J., Schrader, J., Mann, H., \& Noring, R. (1992). Einflu BS der beruflichen Tatigkeit auf den Blutdruckverlaufuber 24 Stunden [BS influence on occupational activity on the blood pressure profile during 24 hours]. Nieren und Hochdruckkrankheiten, 10, 466-468.

Treiber, F. A., Kamarck, T., Schneiderman, N., Sheffield, D., Kapuku, G. \& Taylor, T. (2003). Cardiovascular reactivity and development of preclinical and clinical disease states. Psychosomatic Medicine, 65, 46-62.

Veraksa, A. N., Gorovaya, A. E., Leonov, S. V., Pashenko, A. K., \& Fedorov, V. V. (2012). The Possibility of Using Sign and Symbolic Tools in the Development of Motor Skills by Beginning Soccer Players. Psychology in Russia: State of the Art, 5, 473-497. doi: 10.11621/ pir.2012.0030.

Wyss, J.M., \& Carlson, S.H. (2001). The role of the nervous system in hypertension. Current Hypertension Reports, 3, 255-262. doi: 10.1007/s11906-001-0048-0

Zinchenko, Yu. P., Pervichko, E.I., \& Martynov, A.I. (2013). Psychological underpinning of personalized approaches in modern medicine: syndrome analysis of mitral valve prolapsed patients. Psychology in Russia: State of the Art, 6(2), 89-102. doi: 10.11621/pir.2013.0208

Zubcevic, J., Waki, H., Raizada, M.K., \& Paton, J.F.R. (2011). Autonomic-immune-vascular interaction: an emerging concept for neurogenic hypertension. Hypertension, 57(6), 1026-1033. doi: 10.1161/HYPERTENSIONAHA.111.169748

Received: 01 August 2013

Accepted: 09 September 2013

Available Online: 27 November 2013 